\title{
WHITE GOLDS: A REVIEW OF COMMERCIAL MATERIAL CHARACTERISTICS $\&$ ALLOY DESIGN ALTERNATIVES
}

\author{
Greg Normandeau \\ Imperial Smelting \& Refining Co. of Canada Ltd., \\ Markham, Ontario, Canada
}

White gold alloys became popular in the 1920s as alternatives to platinum in certain types of diamond-set jewellery. In this article the author reviews the status of white gold alloy technology today and the efforts that have been made to improve the properties of these materials.

The expression 'white gold' is a contradiction in terms. Much of the appeal of gold rests with its unique yellow lustre and resistance to tarnish. This distinct colour can be transformed to a greyish white shade to simulate the appearance of platinum. The brilliance of a diamond is greatly enhanced when securely fastened in a bright white gold setting. Patents issued for white gold formulas in the 1920s to Koch [1], Taylor [2], and Wise [5] sought to create a material of assured supply that was cheaper and easier to alloy and fabricate than platinum. The resultant materials, based primarily on gold-nickel-copper-zinc, gold-palladium-silver or other combinations of these elements, possess a number of positive as well as negative features.
Many of the properties most desired from white gold alloys conflict with the basic metallurgical relationships between the elements required to produce them. This subject has been explored by various authors in recent years in an attempt to minimize the shortcomings of the materials and explore potential alternative alloy compositions. With today's greater vigilance regarding the allergenic effects of nickel in contact with skin, this exploration may have greater significance. The whitening or bleaching of gold, and other alloy design considerations, are reviewed and explored below to highlight the compromise of desirable properties that accompanies the usage of white gold materials in jewellery. 


\section{THE BLEACHING OF GOLD}

The characteristic hue of gold is caused by a sharp change in the reflectivity for incident light at a wavelength or energy level corresponding to the colour yellow: According to Saeger and Rodies [6], absorption processes attributed to atomic structure and the transition of electrons from low energy orbitals to the higher energy conduction band cause the unique yellow shade of gold. Most metallic elements exhibit reflectivity behavior that is insensitive to the energy level or wavelength of light, thus appearing essentially grey-white in colour. Figure 1 depicts the reflectance curve for gold compared to platinum and rhodium. Alloying additions to gold cause a shift in its unique reflectivity curve to an intermediate level relative to the levels for the two or more elements involved. Effectively, bleaching of gold is caused by altering the reflectivity of the lower energy segment of the visible spectrum.

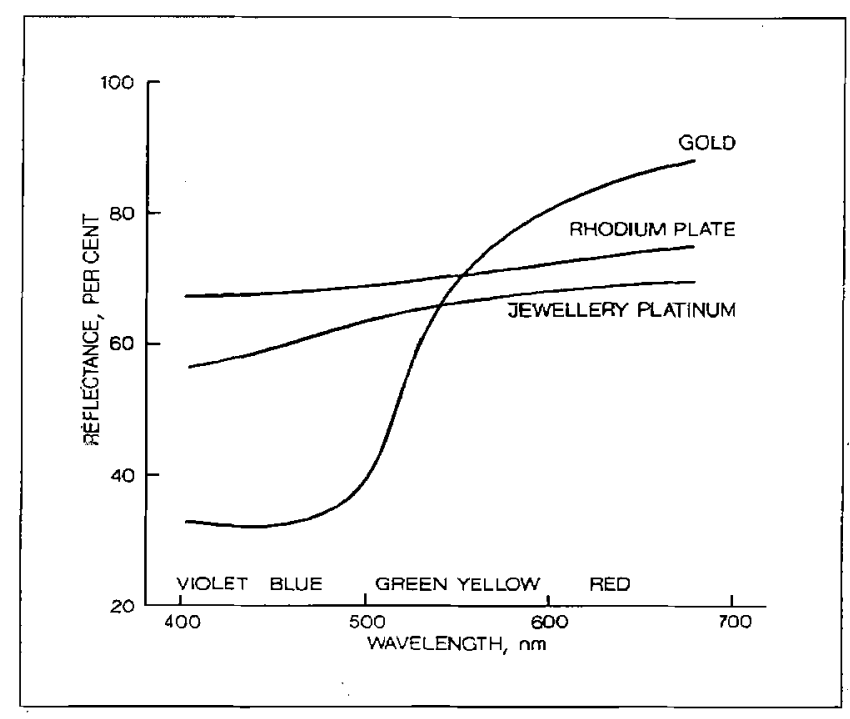

Figure 1

Experimental spectral reflectance curves for pure gold, electrodeposited rhodium and for the 95 platinum/5 copper weight per cent alloy (after [7])

Several authors have investigated this subject as it relates to commercial white golds or experimental materials. Employing common sense restrictions relating to solubility with gold, lack of toxicity, limited reactivity and lower intrinsic value than gold, O'Connor established a list of potential bleaching agents as fol- lows: aluminum, cobalt, chromium, copper, indium, iron, magnesium, manganese, nickel, niobium, palladium, silver, tantalum, tin, titanium, vanadium and zinc [9]. Further restrictions relating to hardness, cold workability and decolouring effect shortened the list of potential primary bleaching agents to silver, palladium, nickel and iron with secondary status reserved for cobalt, zinc, indium and chromium. But potential commercially applicable materials must fulfill numerous other requirements besides having a pleasing white colour.

\section{REQUIREMENTS FOR COMMERCIAL WHITE GOLD MATERIALS}

To qualify as materials suitable for jewellery fabrication, carat white golds must possess a number of physical attributes. As summarized by O'Connor, these include the following:

\section{Primary Requirements:}

1. Suitable white colour and high reflectivity.

2. A reasonable hardness in the as cast or annealed state (arbitrarily a Vickers hardness of less than $200 \mathrm{HV})$.

3. Adequate cold workability (arbitrarily, greater than $25 \%$ elongation under tensile loading).

4. A liquidus temperature suitable for conventional manufacturing techniques (arbitrarily, less than $1100^{\circ} \mathrm{C}$ ).

5. Alloying constituents must be the least expensive necessary to impart the desired properties.

\section{Secondary Requirements:}

6. Materials must be amenable to soldering or brazing techniques for assembly.

7. Materials must be amenable to rhodium plating for colour enhancement.

8. Susceptibility to fire cracking must be minimized.

9. Recycling of process scrap must be possible with no significant difficulties.

10. Materials must be resistant to tarnish and corrosion.

The achievement of these ten attributes simultaneously is very difficult given the metallurgical limitations of the elements employed for fabricating commercial white golds. Compromises between the require- 


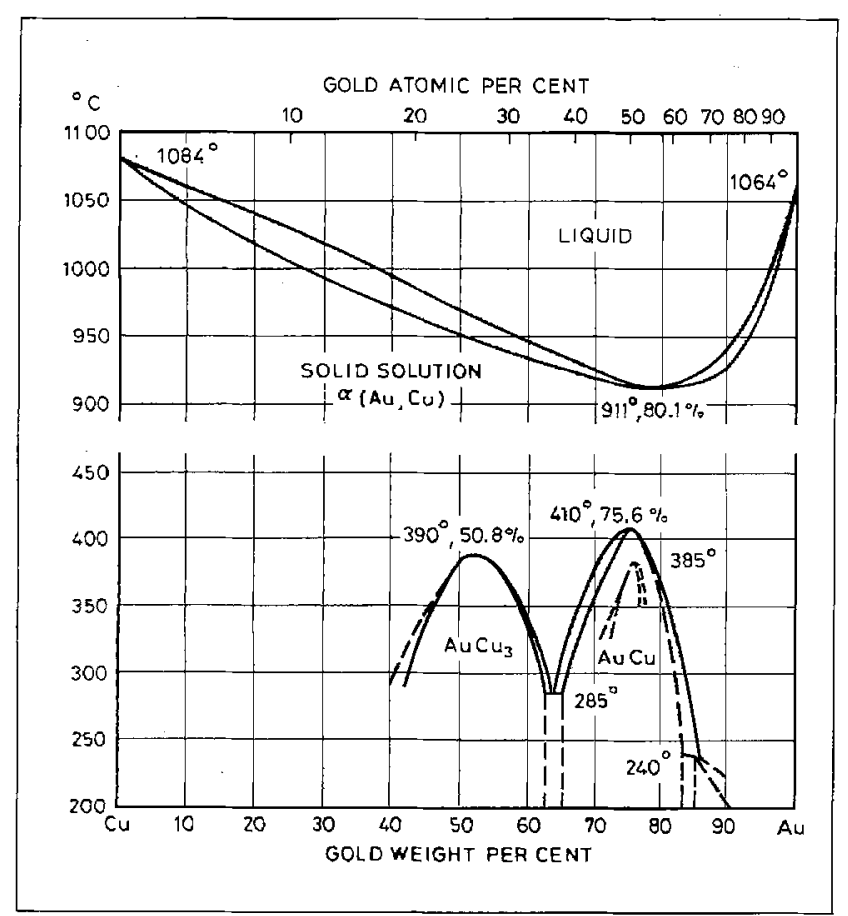

Figure 2

The copper-gold phase diagram illustrating solubility with an order-disorder reaction (after [16])

ments are routinely made with conventional materials. Numerous general overviews of white gold metallurgy discuss these attributes and compromises [12-15]. Detailed consideration of nickel-containing white golds from a North American perspective was undertaken by McDonald and Sistare [16]. Similarly, Susz and Linker reviewed palladium-containing white golds from a European perspective [17]. These two categories of materials will be discussed individually because the distinction is economic rather than metallurgical.

\section{NICKEL WHITE GOLDS}

These materials are based upon additions of nickel, copper and zinc to the appropriate quantity of gold. When considering fulfillment of the ten desirable characteristics, nickel-containing white golds possess a number of positive features. These include the following:

- inexpensive alloying constituents

- good colour match with platinum in 18 carat formulations

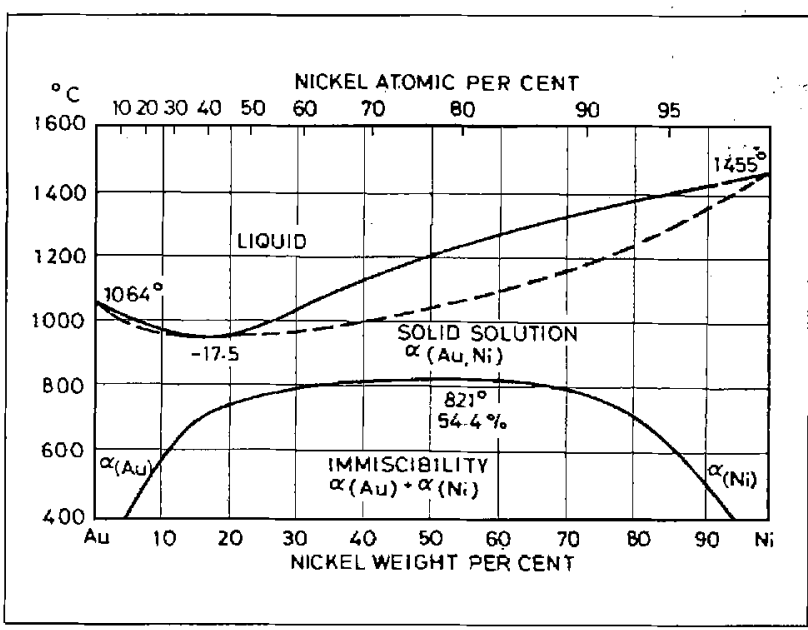

Figure 3

The gold-nickel phase diagram depicting separation of a solid solution to a pair of solid solutions of different physical properties and chemistry (after [1G])

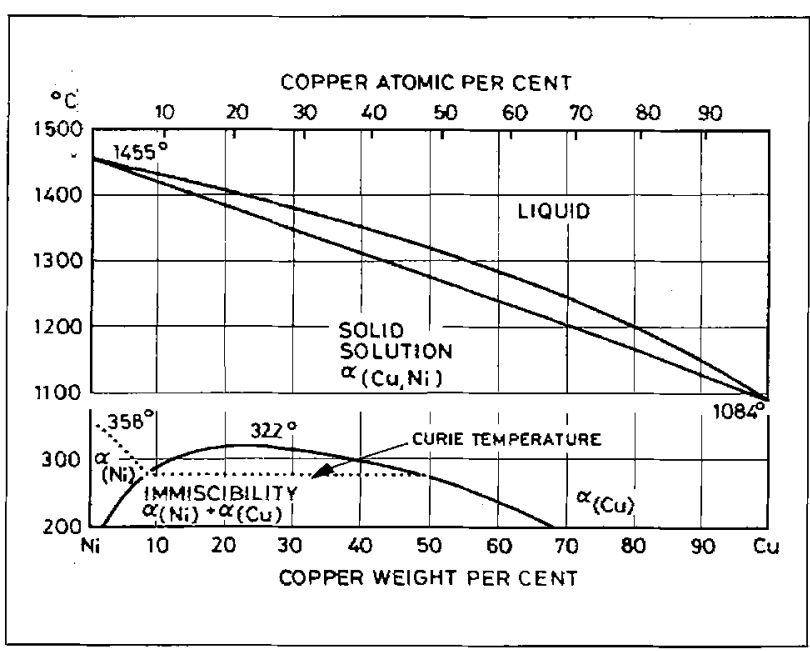

Figure 4

The nickel-copper phase diagram depicting a solid solution relationship with minor separation into two phases at low temperatures (after [16])

- suitability for rhodium plating

- reasonable tarnish resistance

- liquidus temperatures less than $1100^{\circ} \mathrm{C}$.

Conversely, they also exhibit a number of negative attributes, which can be summarized as follows:

- excessive hardness as cast

- poor workability: rapid hardening from cold working 


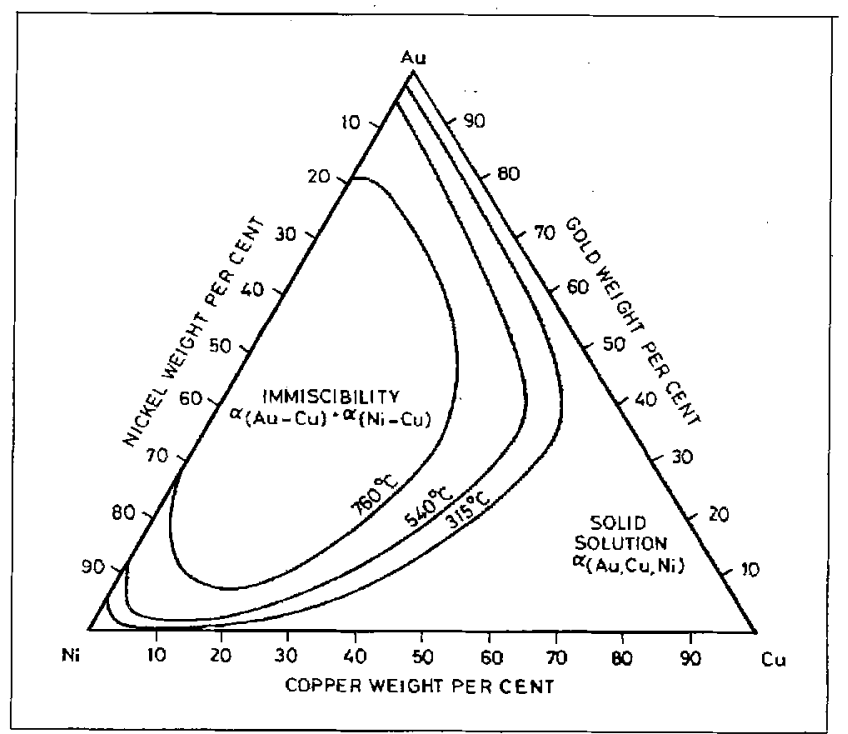

Figure 5

Projection on the room temperature plane of the gold-copper-nickel ternary phase diagram of some isothermal solid-state boundaries of the immiscibility field (after [16])

- poor colour match with platinum in the case of 10 and 14 carat alloys

- poor resistance to fire cracking

- high zinc contents can prejudice recycling.

Each of the alloying elements has a particular function within the material. The physical properties of the commercial materials can therefore be discussed in terms of the binary phase relationships of the alloying metals with gold. Figures 2 to 6 summarize the pertinent data.

The gold-nickel relationship dominates the properties of white golds. Nickel is the primary whitener in these alloys. The binary liquidus minimum of approximately $920{ }^{\circ} \mathrm{C}$ at $82.5 \% \mathrm{Au} 17.5 \% \mathrm{Ni}$ provides for ease of melting. The solid state separation of gold-nickel alloys below $821{ }^{\circ} \mathrm{C}$ into gold rich and nickel rich phases produces considerable hardness and sacrifices formability while lowering corrosion resistance. This separation dominates the ternary goldnickel-copper system over a broad range of commercial compositions. While the order-disorder reaction between gold and copper produces considerable hardness in red materials, the predominant use of copper in white golds is to impart workability especially to lower carat alloys. The upper limit to copper additions is based on a compromise between colour and formability. Larger additions utilized to impart cold working properties degrade the white colour towards a yellowish shade necessitating correction by rhodium plating. This practice, which also lowers the susceptibility towards brittle fire cracking, has become commercially acceptable over the years $[15,18]$.

Zinc usage as a secondary whitener is also restricted by an increasing tendency towards fire cracking and impairment of alloy physical properties. Small additions (1-4\%) provide protection from oxidation during melting and improved wetting of gypsum-based casting investment. Commercial materials normally sacrifice the brightest white colour with its poor formability, high hardness and susceptibility to fire cracking for desirable ductility, lower hardness and a poorer white shade corrected by rhodium plating. Nickel white golds have the decided advantage of utilizing the lowest cost alloying additions.

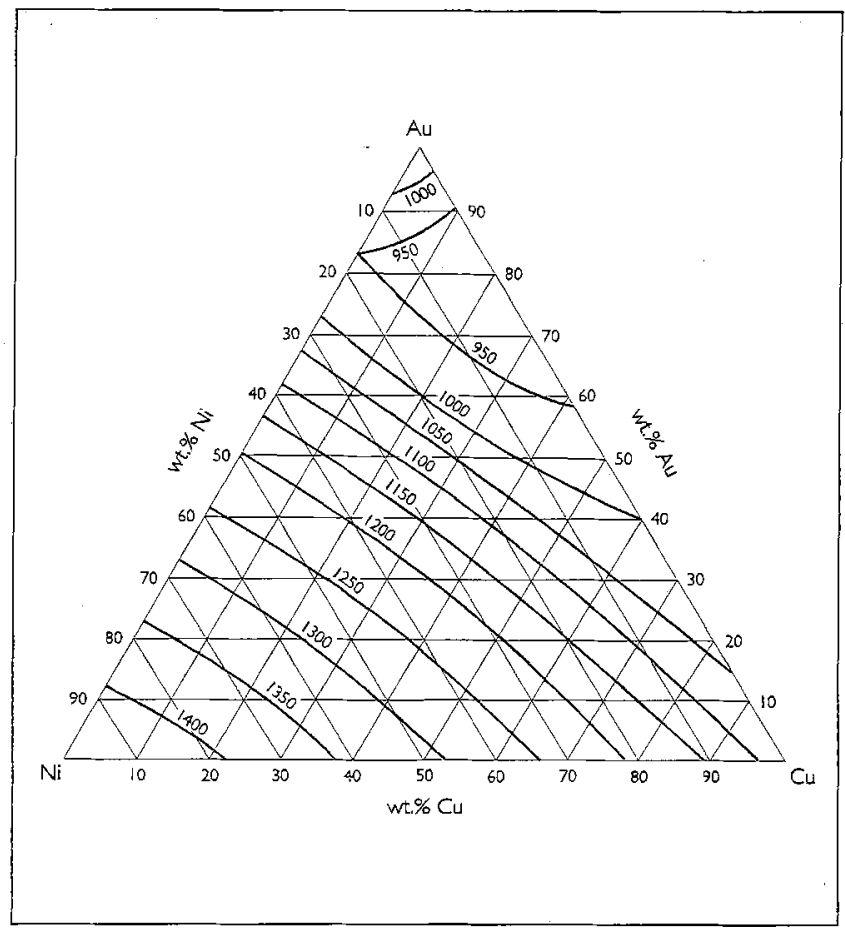

Figure 6

The ternary gold-copper-nickel liquidus temperature $\left({ }^{\circ} \mathrm{C}\right)$ as a function of composition (after [15]) 


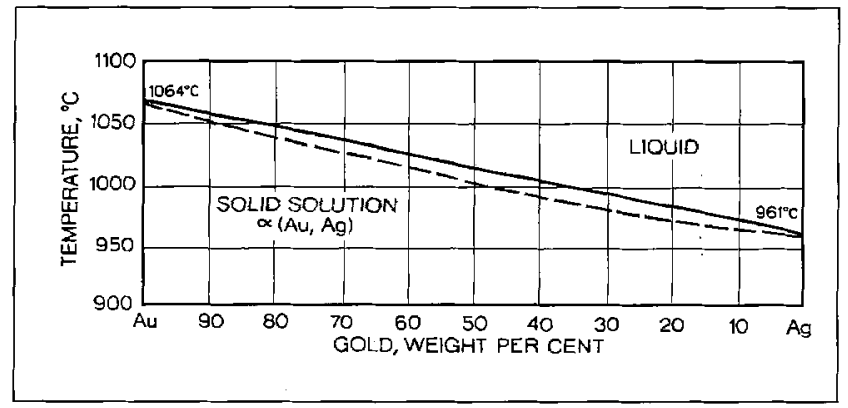

Figure 7

The gold-silver binary relationship indicating complete solid solubility (after [20])

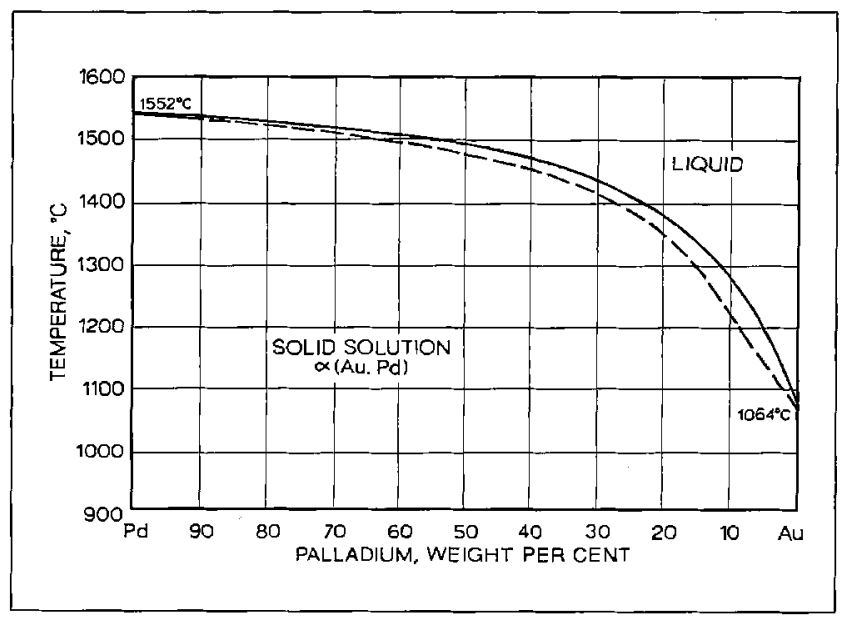

Figure 8

The palladium-gold binary relationship indicating complete solid solubility (after [20])

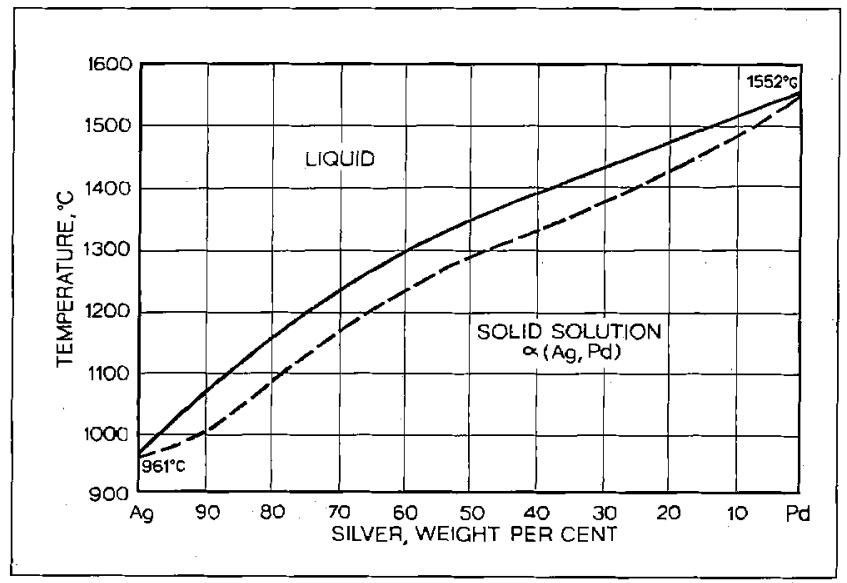

Figure 9

The silver-palladium binary relationship illustrating solid solubility at all compositions (after [20])

\section{PALLADIUM WHITE GOLDS}

The increased cost of palladium discourages its use as an alloying addition, despite a number of superior metallurgical characteristics of palladium white golds as compared to nickel white golds. Palladium based materials possess a number of desirable properties:

- excellent colour match with platinum

- low hardness as cast or rolled

- superior ductility and cold working properties

- ease of soldering or brazing

- no susceptibility to fire cracking

- good corrosion and tarnish resistance

- simple to recycle.

Negative attributes can be summarized as follows:

- alloying additions (Pd) are comparatively expensive

- liquidus temperatures often exceed $1100^{\circ} \mathrm{C}$.

These properties are in contrast to those of nickel golds and can be understood by examining the binary relationships between the elements. Figures 7 to 11 summarize the pertinent information. The gold-silver, goldpalladium and silver-palladium binary relationships all indicate complete solid solubility throughout the full range of compositions. These solid solutions are extremely ductile, soft and corrosion resistant provided sufficient palladium or gold is present. The range of strong whitening provided by palladium is very broad, as illustrated by Figure 10. Small additions of palladium to gold cause a rapid rise of melting temperature.

Figure 11 summarizes the liquidus temperature for the ternary gold-palladium-silver system. Compositions over a broad range of the ternary relationship possess a liquidus in excess of the arbitrary target of $1100^{\circ} \mathrm{C}$. Beyond that temperature, the tendency for molten metal to decompose calcium sulphate investment into detrimental sulphur dioxide gas becomes an issue. Materials that have low palladium and high silver content are susceptible to tarnish through reactions with sulphur. Commercial compositions normally address this issue by providing protection through the addition of sufficient noble palladium. The solid state phase separation that contributes to the compromise of properties inherent in nickel white golds does not occur with palladium white golds. Provided the increased cost factor and elevated melting temperatures are not too restrictive, these materials exhibit numerous desirable properties. 


\section{ALTERNATIVE WHITE GOLD FORMULATIONS}

Extensive work reported by a number of authors explored alternative formulations to overcome the inherent limitations of either the gold-nickel-copper-zinc system or the gold-palladium-silver system. This was predominantly focussed on 18 carat alloys used extensively in Europe with virtually no specific discussion of potential 10 and 14 carat formulations favoured in North America. Investigation aimed at creating nickelfree materials with complete commercial applicability was not undertaken. Some of the significant aspects and conclusions of this work warrant separate discussion.

\section{ADDITIONS OF Ni-Cu-Zn TO WHITE GOLDS BASED ON Au-Pd-Ag}

Work by Susz and Linker advocated a different approach to alloy design $[17,19]$. As previously noted, the mutual solubility relationship between gold, palladium and silver results in a gradual transition of properties such as hardness, ductility and melting range over a broad range of compositions that are sufficiently white for commercial application. Relatively small additions of nickel, copper and zinc to a basic gold-palladium-silver white gold result in orderly and progressive improvements in properties.

This approach removes the traditional separation of materials into nickel or palladium white gold in an attempt to blend the properties of the two alloy systems and overcome their limitations by a sharing of properties.

Test results indicated that nickel-copper-zinc additions to a gold-palladium-silver ternary of suitable whiteness caused predictable incremental increases of hardness while simultaneously decreasing ductility. The overall percentage of nickel-copper-zinc added was the determining factor, not the specific ratios of the three elements themselves. Likewise, the specific percentages of palladium and silver employed with gold were not a significant factor for determining the overall properties. These results could allow for the formulation of complex six-

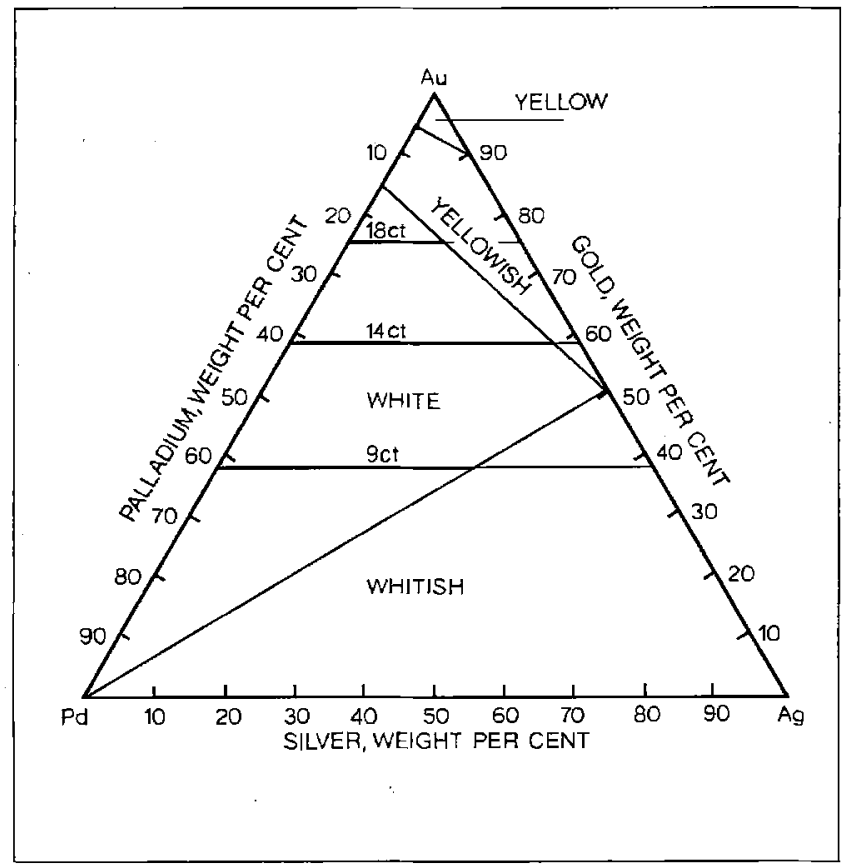

Figure 10

The gold-silver-palladium ternary colour diagram indicating the range of whiteness as a function of composition (after [20])

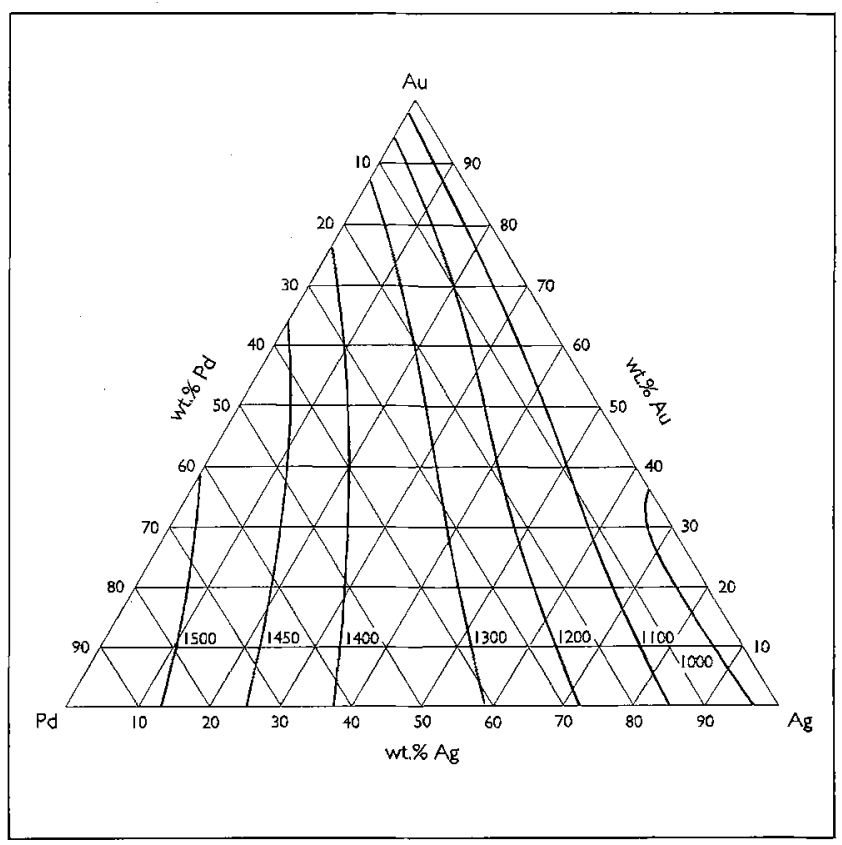

Figure 11

The gold-silver-palladium ternary liquidus diagram illustrating a gradual transition of temperature with changing composition (after [15]) 
element alloys by relatively simple proportioning techniques to produce a desired combination of ductility and hardness. The study compared the properties and compositions of commercially available European 18 carat white golds without specific reference to the variables of cost or melting temperature. Application of this methodology to 10 and 14 carat materials could significantly simplify a complicated design problem.

\section{QUANTITATIVEASSESSMENT OF GOLD BLEACHING ELEMENTS}

MacCormack and Bowers [7], as well as German et al. [20], employed the CIELAB colour coordinate system with a spectrophotometer to assess objectively the relative decolourizing efficiencies of various elements in order to facilitate the design of white gold alloys. Employing the metric chroma value as a measure of whiteness, with reference points 0 for white and 40 for pure gold, they were able to quantify and predict the bleaching effect of an alloying addition.

Three primary bleaches, identified and ranked on ability to decolourize, were palladium, iron and nickel. Significantly, when the limits of solubility and $25 \%$ weight additions were achieved with these bleaching elements, a metric chroma value of 5 or 6 was the best that could be attained in comparison to a value of 3 for rhodium or 4 for platinum jewellery alloys. This indicated that the human eye, with its ability to discern differences of about 1 metric chroma unit, would be able to differentiate between these two materials.

They established a metric chroma value limit of 9 for usage without rhodium plating, and plotted values for a number of experimental and commercial materials to test compliance with this criterion. Experimental compositions contained $75 \%$ gold, $10 \%$ palladium plus iron, copper, silver and zinc. The restriction of palladium content by substitution with iron to achieve a similar desirable colour was done to address cost concerns. With a similar colour, these alloys contained between 2 and $7 \%$ less Pd than other commercial materials. Hardness was purportedly 120 to $150 \mathrm{HV}$ indicating potential usage for jewellery applications. No other significant physical properties such as percentage elongation or liquidus were discussed. While it is unfortunate that work was not extended to 10 or 14 carat materials, objectivity of colour measurement and extension of the principle to alloy design was established.

\section{MODIFIED \\ WHITE GOLD FORMULAS}

Investigations by O'Connor at BNF Metals Technology Centre documented consideration of numerous alternatives to conventional white golds $[9,10]$. Employing the list of elements noted previously, $\mathrm{O}^{\prime} \mathrm{Con}$ nor evaluated decolourizing of gold, material hardness and workability over a range of concentrations up to the 25 weight percent allowed in an 18 carat alloy. Preliminary results indicated that only silver, cobalt, nickel or palladium formed workable binary solid solutions with gold, whereas both iron and chromium formed terminal solid solutions with poor workability. Other elements gave rise to varying amounts of brittle intermetallics rendering them impossible to cold work. These binary materials exhibited various shortcomings such as excessive hardness (Au-Ni), poor colour ( $\mathrm{Au}-\mathrm{Co}, \mathrm{Au}-\mathrm{Ag}$ ), a high melting range (Au-Pd) and poor corrosion resistance $(\mathrm{Au}-\mathrm{Fe})$. Detailed work on gold combinations with palladium, cobalt and silver was not done because of excessive cost or barely acceptable colour. A diverse range of ternary combinations of gold with iron or nickel was investigated to address the binary shortcomings.

\section{Gold-Iron \\ Alloys}

Additions of chromium, cobalt, nickel, tin, zinc or indium alone or in various combinations did not improve the poor workability of gold-iron alloys. The results implied that iron could not serve as a primary whitener for gold.

\section{Gold-Nickel \\ Alloys}

Attempts to reduce the excessive hardness of gold-nickel alloys were only partially successful. Palladium additions which improved colour did not lower hardness. Silver additions which lowered hardness impaired colour. Ad- 
ditions of tin, indium or chromium impaired physical properties. Only cobalt lowered hardness without significant detriment.

\section{Gold-Nickel-Cobalt Alloys}

Ternary mixtures of these elements exhibited a coarse microstructure unsuitable for jewellery applications. Increasing the cobalt-nickel ratio lowered hardness but
Additions of not more than $2 \%$ of indium, zinc, chromium or copper lowered the ternary material hardness without impairing colour. Substitution of nickel with iron was possible without any detrimental effects. Final recommendations from O'Connor called for a complex 18 carat alloy of gold, nickel, iron, cobalt, chromium and indium. This material purportedly exhibited a hardness of $200 \mathrm{HV}$ in the annealed condition, a liquidus below $1100{ }^{\circ} \mathrm{C}$ and a suitable white colour. Specific design strategies

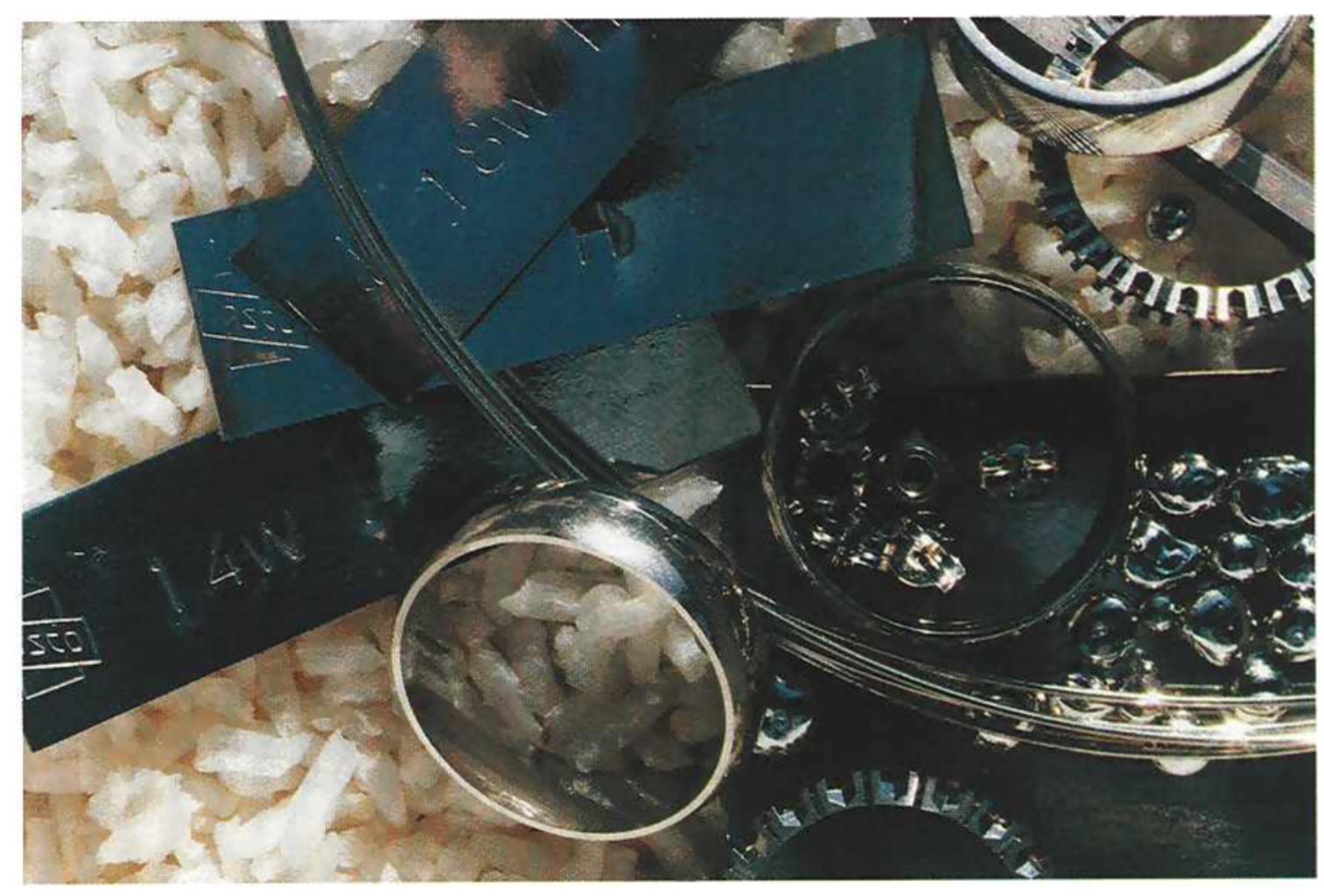

Figure 12

Assorted white gold semi-finished products for a varied range of jewellery applications: seamless bands, casting grain, solders, wire, settings, plate products

impaired colour. Investigations to further improve properties focussed on additions of silver, tin, indium, zinc, chromium, copper or palladium. Tin and silver additions were rejected because of embrittlement or colour impairment, respectively. for 10 or 14 carat materials were not discussed. The broad range of combinations considered provided insight into the behavior of metallurgically complex materials. 


\section{Nickel-free White Golds}

The complete elimination of nickel from white golds was not specifically discussed in the reference studies. Consideration of 18 carat palladium-silver white golds indicated that nickel additions lower the melting range, improved the colour and allowed for controlled hardness increases to the desired level [21]. These changes would generally be considered as improvements. Nickel is the primary bleaching agent used in most of the commercial white golds in North America.

Numerous European formulas rely on nickel, alone or in combination with palladium and silver, for bleaching of gold. Complete replacement of nickel with either palladium or iron has metallurgical or economic limitations. Evaluation of various 18 carat nickel white gold compositions with the standard test procedures to determine suitability as regards avoiding nickel allergenic reactions may reveal that the high gold content is adequate to ensure that the alloy is sufficiently inert for jewellery applications. The lower gold content associated with 10 or 14 carat materials, however, may not provide suitable corrosion resistance to withstand these tests. It is very unlikely that a suitable material can be developed without the use of both nickel and palladium.

\section{FURTHER RESEARCH}

Extension of the work of various authors on 18 carat formulations common in Europe to 10 and 14 carat materials common in North America is necessary. Concurrently, nickel-free formulas should also be studied. The corrosion behavior of large quantities of cobalt, iron or silver with palladium is worthy of evaluation. Lower carat materials may require the use of extensive quantities of copper, thus altering the relationship between gold and other alloying additions. Indium may prove a suitable bleach in the presence of large copper additions. It may also provide a cheaper source of corrosion resistance for high silver materials than palladium, while lowering material melting ranges. Detailed documentation of objective physical properties such as colour, cast hardness, wrought hardness, yield strength, tensile strength, percentage elongation, liquidus and solidus will provide a basis for comparison of various formulas. Numerous other relationships are worthy of further research, given the stature of white golds in today's jewellery products.

\section{CONCLUSIONS}

Many avenues for further exploration of alternative white gold formulas exist. Given the shortcomings of nickel based materials, alternatives may sacrifice cost and melting temperature to provide better colour, formability and resistance to fire cracking. Palladium based materials must conform to conventional investment casting technology and minimize cost. Alternative materials that have been explored in detail for 18 carat compositions, must be developed for the 10 and 14 carat gold standards. Thorough and objective documentation of physical properties possessed by conventional materials will allow comparison with new alternatives. Compromise between colour, hardness, formability, melting temperature, fire cracking resistance, corrosion resistance and material cost will continue to be an issue.

Given the vast amount of study these materials have received in the past, the chance of a simple solution without compromise appears remote. Development of nickel-free white golds with all the requisite properties and minimum content of expensive palladium is a significant challenge. Nonetheless, the widespread use of white gold justifies the efforts as many a frustrated jeweller will find improved materials a welcome and, indeed, overdue change.

\section{Acknowledgments}

The diligent and thoughtful assistance of Imperial Smelting and Refining Metallurgical Engineer Rob Roeterink has been an asset from the outset of this project. The 1992 Santa Fe Symposium served as a forum for initial presentation of this material. The results of studies on white gold materials at Imperial Smelting and Refining in 1992 and 1993 will be presented at the 1993 Symposium. 


\section{References}

1. T. Koch, United States Patent 1340451, 18 May 1920

2. N. Taylor, United States Patent 1987451, 8 January 1935

3. G. Sistare, E. Chamer, United States Patent 3512961 , 19 May 1970

4. E.M. Wise, United States Patent 2050077, 4 August 1936

5. E.M. Wise, United States Patent 1577995, 23 March 1926

6. K. Saeger, Rodies, J., 'The Colour of Gold and Its Alloys', Gold Bull. 1977, 10(1), 10-14

7. B. MacCormack, J. Bowers, 'New White Gold Alloys', Gold Bull: 1981, 14(1), 19-24

8. J. Atkinson, 'The Bleaching of Gold to Produce White Gold' The Worshipful Company of Goldsmiths T.A.C. Project No. 6a/2, June 1972

9. G. O'Connor, 'Improvement of 18 Carat White Gold Alloys', Gold Bull. 1978, 11(2), 35-39

10. G. O'Connor, 'Alloy Additions for 18 Carat White Gold Jewellery Alloys', Metals Technology, July 1979, pp. 261-266

11. G. Raynor, 'The Alloying Behavior of Gold', Gold Bull. 1976, 9(1), 12-19
12. L.S. Bonner et al., 'Precious Metals Science and Technology', IPMI, 1991, pp. 440-446

13. L. Gal-Or, 'Gold Alloys', Santa Fe Symposium 1987, Met-Chem Research 1988, pp. 57-74

14. W.S. Rapson, 'Gold Usage', Academic Press, London, 1978, pp. 41-87

15. E. Wise, 'Gold: Recovery, Properties and Applications', D. Van Nostrand, Princeton, 1964, pp. 66-93, 97-153

16. A. McDonald, G. Sistare, 'The Metallurgy of Some Carat Gold Jewellery Alloys', Gold Bull. 1978, 11(4), 128-131

17. C. Susz, M. Linker, ' 18 Carat White Gold Jewellery Alloys', Gold Bull. 1980, 13(1), 15-20

18. Metals Handbook, 9th Edition, Volume 2, American Society for Metals, 19XX, pp. 680-683

19. C. Susz, '18 Carat White Gold Alloys', Aurum 4, 1980, 11-22

20. R. German, M. Guzowski, D. Wright, "The Colour of Gold-Silver-Copper Alloys', Gold Bull. 1980, 13(3), 113-116

21. B. Taylor 'The Work Hardening of 18 Carat White Gold', The Worshipful Company of Goldsmiths T.A.C. Project No. 31, May 1978 